e-ISSN: 2359-5078

\title{
Importância do mix de marketing nos negócios educacionais
}

Importance of marketing mix in educational business

\author{
Adailton Roberto de Morais ${ }^{1 *}$, João Batista de Camargo Junior ${ }^{2}$
}

1*UNICEP - Bacharel em Administração - Rua Durvalino Gonçalves da Silva, 529 - JdSão João Batista - 13567-000 - São Carlos, SP - Brasil <adailtonrob@gmail.com>

${ }^{2}$ UNIMEP - Doutor em Administração - Rodovia do Açúcar, Km 156 - Taquaral - 13423-170 - Piracicaba, SP - Brasil

\section{Resumo}

O mix de marketing simplificado, composto pelos elementos produto, preço, praça e promoção, é uma ferramenta essencial para a obtenção de vantagem competitiva e alavancagem nas vendas de produtos e serviços. Nesse contexto, o objetivo desse estudo foi identificar a importância do mix de marketing para uma empresa educacional do setor privado na comercialização de seus serviços em relação as possibilidades de alavancar as vendas e gerar vantagem competitiva. Para atingir esse objetivo foi realizada uma pesquisa exploratória através de um estudo de caso, além da análise de livros e artigos acadêmicos para fundamentação do tema da pesquisa. Em relação ao elemento produto, o estudo demonstrou sua importância nas decisões de compras dos consumidores. Quanto ao preço, foi constatado que a empresa possui uma política bem definida e reconhecida pelos clientes. Através da concessão de descontos consideráveis em 2017, suas vendas foram alavancadas, o que a tornou mais competitiva frente à concorrência. Relacionado à praça, foi diagnosticado que a empresa investe em excelência e capilaridade, tornando sua oferta ainda mais acessível a todo tipo de público e ocupando o espaço da concorrência. Quanto à promoção, o estudo identificou que a empresa realiza ações promocionais pontuais visando o público de massa e que seria importante a realização de ações promocionais voltadas à segmentação do mercado. Através desses elementos, o estudo aponta que o mix de marketing tem grande importância para alavancar as vendas e conquistar vantagem competitiva.

Palavras-chave: praça, preço, produto, promoção, vantagem competitiva

\begin{abstract}
The simplified marketing mix, made up of product, price, place and promotion elements, is an essential tool for gaining competitive advantage and leverage in sales of products and services. In this context, the objective of this study was to identify the importance of the marketing mix for a private sector educational company in the commercialization of its services in relation to the possibilities of leverage sales and generate competitive advantage. In order to achieve this objective, an exploratory research was carried out through a case study, as well as the analysis of books and academic articles to substantiate the research theme. Regarding the product element, the study demonstrated its importance in consumer purchasing decisions. Regarding the price, it was verified that the company has a well defined policy and recognized by the customers. By granting considerable discounts in 2017, its sales were leveraged, which made it more competitive against the competition. Related to the place, it was diagnosed that the company invests in excellence and capillarity, making its offer even more accessible to all types of public and occupying the space of the competition. Regarding the promotion, the study identified that the company carries out specific promotional actions aimed at the mass public, and that it would be important to carry out promotional actions aimed at market segmentation. Through these elements, the study points out that the marketing mix has great importance to leverage sales and gain competitive advantage.
\end{abstract}

Keywords: place, price, product, promotion, competitive advantage

\section{Introdução}

Impulsionada pelas comunicações globais, evolução da tecnologia e dos negócios, urbanização e baixo custo da mão de obra, acontece a maior migração de mão de obra desde a revolução industrial: a migração da agricultura e da manufatura para os serviços. O setor de serviços é líder em todos os países industrializados, gerando novos empregos e com potencial para melhoria da qualidade de vida. Muitas implicações surgem com as mudanças nos tipos de emprego e as principais se referem aos lugares onde as pessoas vivem, como vivem, necessidades educacionais e, por consequência, os tipos de organizações que terão importância para a sociedade (Fitzsimmons e Fitzsimmons, 2014). 
Testemunha-se, portanto, o início da chamada "Quarta Revolução Industrial", que tem o potencial de alterar profundamente a maneira como as pessoas vivem, trabalham e se relacionam. Mudanças importantes têm ocorrido em todos os setores, tendo em vista o surgimento de novos modelos de negócios e pela reformulação da produção, do consumo, dos transportes e dos sistemas logísticos (Schwab, 2016).

Particularmente nas três últimas décadas, as maneiras de fazer negócio tiveram grande alterações. As práticas empresariais que evoluíram em uma era de estabilidade política e econômica não garantem mais a certeza de antes, tendo em vista a velocidade e imprevisibilidade que acontecem. A globalização apresenta ameaças e oportunidades as empresas que só competiam contra concorrentes domésticos (Besanko et al., 2012).

Desse modo, considerando a maior competitividade no mercado, as empresas criaram novas estruturas organizacionais. As organizações precisam se reorganizar, reduzir custos indiretos e redimensionarem-se, além de buscar fusões e parcerias visando criar vantagem competitiva (Hooley et al., 2011). Além disso, devem encontrar o plano para a sobrevivência e o crescimento de longo prazo frente suas oportunidades, seus objetivos e seus recursos específicos no momento e situação na qual se encontram. Esse é o foco do planejamento estratégico - o processo de desenvolver e manter um alinhamento estratégico dos objetivos e habilidades de uma organização com as oportunidades de marketing em um mercado em mutação (Kotler e Armstrong, 2007)

Essa situação também é verificada no setor educacional. Originalmente, a organização de educação não foi pensada como empresa que desenvolvia atividades lucrativas. Entretanto, é extremamente necessário a obtenção de recursos para sua manutenção e continuidade de existência. Instituições de ensino privadas ocuparam uma lacuna deixada pelos governos que não conseguiram atender à demanda existente na área educacional. Assim, é possível encontrar instituições de ensino com finalidades empresariais ou não (Colombo, 2008).

Visando estabelecer uma relação com os clientes e ainda agregar valor aos serviços, o uso do conjunto de ferramentas de marketing é estratégico para as organizações como um todo, incluindo as educacionais (Churchill Jr e Peter, 2003).

Os elementos produto, preço, praça e promoção compõem o chamado mix de marketing, uma ferramenta que as empresas utilizam para a definição e realização de suas estratégias de marketing. Toda a estratégia de marketing é transformada em ação durante o relacionamento que o programa de marketing estabelece com o cliente (Kotler e Armstrong, 2007).

Tendo em vista os serviços serem produzidos e consumidos simultaneamente, os clientes interagem com os prestadores de serviços, fazendo assim parte do processo de geração dos mesmos. Outro ponto importante nos serviços é a intangibilidade, tendo em vista serem ações e execuções e não bens físicos. Os profissionais de marketing, observando a importância dessas variáveis adicionais, adotaram o conceito de mix expandido do marketing de serviços, que além dos 4Ps tradicionais do mix de marketing, inclui pessoas, evidência física e processo (Zeithaml et al., 2014).

Nesse contexto, o objetivo desse estudo foi identificar a importância do mix de marketing na comercialização de serviços educacionais em relação as suas possibilidades de alavancar as vendas de cursos e eventos educacionais e gerar vantagem competitiva.

\section{Material e Métodos}

Em busca de aprofundamento, maior conhecimento sobre o tema do estudo e visando atingir seu objetivo foi realizada uma pesquisa exploratória através de um estudo de caso. Também foram analisados livros e artigos acadêmicos em busca de construções teóricas que fundamentassem o tema do estudo.

Apesar de muitos profissionais do marketing utilizarem o conceito do mix de marketing expandido, este estudo se limita a analisar os 4 Ps clássicos do mix de marketing, sendo: produto, preço, praça e promoção, criado pelo professor Jerome McCarthy e amplamente difundido e popularizado por profissionais como Philip Kotler e Kevin L. Keller (Kotler e Keller, 2012).

Para a coleta de dados e informações foi utilizado o método de levantamento de dados primários através da realização de um estudo de caso qualitativo, bem como levantamento de dados secundários internos e externos. A unidade de análise desse estudo é uma empresa que desde sua criação, em 1946, passou a ser o principal agente de educação profissional voltado ao setor do comércio de bens, serviços e turismo do país. É uma entidade privada, mantida pelos empregadores do comércio

Em seu portfólio constam cursos presenciais e a distância nas mais diversas áreas do conhecimento, voltados para a formação inicial e continuada, cursos técnicos e educação superior (graduação e pósgraduação). Hoje, presente em mais de 2.200 municípios, de Norte a Sul do Brasil, onde mantém infraestrutura de ponta composta por mais de 600 unidades escolares, empresas pedagógicas e unidades móveis. No estado de São Paulo, está fisicamente presente em mais de 40 municípios, com 60 unidades, além de dois hotéis-escola e de uma editora.

A unidade estudada dessa empresa está localizada no interior do estado de São Paulo, na cidade de São Carlos, há 67 anos com sede própria. Sua atuação abrange não só a cidade de São Carlos, mas também 
sua microrregião, onde estão presentes as cidades de Analândia, Descalvado, Porto Ferreira, Ibaté, Leme, Pirassununga, Itirapina, Ribeirão Bonito, Santa Cruz da Conceição, Santa Cruz das Palmeiras, Santa Rita do Passa Quatro e Tambaú, todas localizadas no interior do estado de São Paulo.

Está presente também nas cidades de Porto Ferreira e Itirapina com dois polos. Esses polos são frutos de parcerias da empresa com os governos municipais de Porto Ferreira e Itirapina, com o objetivo de atender e oferecer cursos profissionalizantes ao munícipes e pessoas das cidades vizinhas.

Nas três cidades onde a unidade está presente a população é de aproximadamente 288.874 pessoas, sendo 221.950 pessoas residentes na cidade de São Carlos, 51.400 pessoas residentes na cidade de Porto Ferreira e 15.524 pessoas residentes na cidade de Itirapina. A população das demais cidades da microrregião onde a unidade estudada atua somadas totaliza 322.873 pessoas. Assim a microrregião que a unidade estudada atende possui a população total de 611.747 pessoas (IBGE, 2010).

A unidade estudada possui prédio próprio com as seguintes áreas, sendo: 8.008,31 $\mathrm{m}^{2}$ de terreno; 3.639,43 $\mathrm{m}^{2}$ construídos; 2.072,43 $\mathrm{m}^{2}$ de ensino; $165,57 \mathrm{~m}^{2}$ de apoio ao ensino; $130,79 \mathrm{~m}^{2}$ administrativa; $1.270,64 \mathrm{~m}^{2}$ de serviço; 729,45 $\mathrm{m}^{2}$ livre.

A área educacional é composta pelos seguintes ambientes: um atelier de "design", um auditório, uma biblioteca, um estúdio de rádio, um laboratório de beleza, um laboratório de cozinha, um laboratório de "hardware", três laboratórios de "softwares", dois laboratórios de multiprocedimentos, um laboratório três em um (enfermagem, farmácia e meio ambiente, dezoito salas de aulas convencionais, totalizando a capacidade para atendimento de 1.061 alunos sentados. Todos os ambientes são equipados com um computador ligado a um projetor multimídia para uso dos monitores educacionais, ambiente climatizado e isolamento acústico.

A área administrativa é composta pelo atendimento ao cliente, setor administrativo, apoio/almoxarifado, sala de servidores, secretaria escolar, setor de coordenação técnica e sala dos monitores educacionais. A unidade é composta por mais de 180 colaboradores, dentre eles funcionários da unidade e de empresas terceirizadas, distribuídos nas áreas administrativas, educacional e de vigilância.

Considerando que a finalidade da coleta de dados é comparar os dados e informações levantadas com os conceitos da literatura existente, foram realizadas entrevistas semiestruturadas na empresa estudada. De um universo de 12 profissionais que poderiam participar das entrevistas, foram intencionalmente selecionados nove colaboradores em função da área que cada um atua e a consequente relação com o tema do estudo, experiência profissional e envolvimento direto com as ações da unidade no que tange ao uso do mix de marketing, conforme relação: Gerente da unidade de São Carlos, gestora da unidade e responsável por todas as decisões e ações desenvolvidas na unidade; três Técnicos de desenvolvimento profissional, responsáveis pelas diversas áreas de negócios dentro da unidade, dentre elas: Tecnologia da Informação, Gastronomia, Gestão e Negócios, Saúde e Bem-Estar, Educação, Hotelaria e Turismo, Meio Ambiente, Segurança e Saúde no Trabalho, Desenvolvimento Social, Comunicação e Artes, Moda, dentre outras; Supervisora educacional, responsável por todas as ações pedagógicas realizadas dentro e fora da sala de aula relacionadas às áreas de negócios; Coordenador administrativo, responsável por toda a área administrativa, de recursos humanos e compras da unidade; Representante da comunicação, responsável pelo planejamento e apoio na definição das ações de comunicação desenvolvidas na unidade; Coordenadora do atendimento, responsável pela coordenação da estratégia de vendas e da equipe de atendimento da unidade; e, Docente especialista, atua como docente da área de gestão e negócios, empreendedorismo, marketing e vendas.

As entrevistas foram realizadas entre os meses de agosto e outubro de 2017 e tiveram duração média de 45 minutos. Ressalta-se que o roteiro das entrevistas foi construído com base na bibliografia pesquisada.

Em visitas ao site da empresa estudada e sua Intranet também foram coletadas informações sobre o perfil da empresa, sua área de atuação, além de sua capilaridade no país e no estado de São Paulo.

Foram utilizados também documentos internos da empresa, denominados, Avaliação de Reação e Projeto Político Pedagógico, com o intuito de levantar características relacionadas à qualidade dos serviços prestados, bem como a intenção de compra para novos cursos. As Avaliações de Reação são avaliações escritas, aplicadas ao final de cada curso realizado, para que os participantes avaliem a qualidade dos serviços prestados, indiquem as áreas de mercado de maior interesse e registrem ainda suas intenções de compra para outros cursos. O Projeto Político Pedagógico é um documento elaborado de forma coletiva, que envolve funcionários, docentes, alunos e toda comunidade do entorno escolar, com o objetivo de desenvolver a proposta educacional, identificando possíveis problemas no projeto educacional e suas respectivas soluções. As Avaliações de Reação analisadas foram aplicadas no período de janeiro a setembro de 2017 e o referido Projeto Político Pedagógico foi desenvolvido entre os anos de 2016 e 2017.

Documentos administrativos e bancos de dados internos também foram consultados, visando conhecer a unidade estudada em relação a seus ambientes e a 
respectiva capacidade de atendimento, além do número de funcionários que atuavam na empresa no período supracitado.

O portal do Instituto Brasileiro de Geografia e Estatística [IBGE] também foi consultado e nele foram levantados dados referentes à população da cidade de São Carlos e sua microrregião. Todos esses dados foram então agregados, compilados e analisados em relação aos preceitos da literatura a fim de atingir o objetivo do estudo.

\section{Resultados e Discussão}

\section{Produto (Serviço)}

O produto (serviço) foi o primeiro elemento do mix de marketing analisado nessa pesquisa. Primeiramente, foram identificados quais foram os principais fatores que levaram os clientes a decidirem pela compra de um serviço da empresa estudada. Posteriormente, foram realizadas análises para saber se a empresa estudada investe na qualificação e no encarreiramento de seus funcionários, tendo em vista a importante contribuição desses investimentos para a melhoria da qualidade na comercialização dos serviços ofertados e também para verificar se o cliente percebe esses fatores como um diferencial competitivo em sua decisão de compra. Dados dos documentos da empresa também auxiliaram a identificar se faz estudos do mercado local visando maior assertividade na atualização do portfólio e consequente vantagem competitiva.

Em relação aos serviços, Kotler e Keller (2012) relataram que os consumidores de serviços depositaram grande confiança nas informações transmitidas pessoalmente. Além disso, afirmaram que o preço e o atendimento são importantes para o julgamento dos consumidores em relação à qualidade e que a satisfação de suas expectativas os fideliza na compra dos serviços. Como a empresa estudada é uma prestadora de serviços na área educacional, os resultados e discussões das entrevistas demonstraram que foram vários os fatores que levaram o cliente a decidir pela compra de um curso na empresa, tais como: política de descontos, infraestrutura, diversificação do portfólio, profissionalismo no atendimento e corpo docente qualificado. Porém, dois fatores se destacaram: a possibilidade de qualificação profissional para o mercado de trabalho e a marca da empresa. Os resultados demonstraram que os itens diagnosticados estão de acordo com a literatura, porém, dependendo do serviço oferecido, outros itens podem ser levados em conta pelo consumidor em sua avaliação sobre a qualidade.

Ainda sobre os serviços, Zeithaml e Bitner (2003) afirmaram que as pessoas exercem papel fundamental na comercialização e entrega dos mesmos, uma vez que a atuação dos funcionários no processo de execução de um serviço pode influenciar a forma como os compradores os percebem. Essa situação está em consonância com o que ocorre na empresa estudada. De acordo com as entrevistas realizadas, ficou evidenciado que a empresa investe na qualificação e encarreiramento de seus funcionários visando a promoção da melhoria da qualidade na comercialização dos serviços. Isso pode ser percebido pelos clientes como um diferencial competitivo na decisão de compra.

Nesse sentido, a empresa manteve um programa chamado Educação Corporativa que incentiva e oferece oportunidades de desenvolvimento das equipes em diversas frentes, técnicas e de desenvolvimento pessoal. Além disso, cada unidade possui atividades regulares de formação, compartilhamento de informações e ações colaborativas que contribuem para o desenvolvimento das equipes. O encarreiramento foi incentivado através de vagas e processos seletivos divulgados regularmente. Existiu ainda uma política de promoções que oscilou em momentos de mais oportunidades e outros de recessão, nos quais foi mais difícil contemplar e incentivar os funcionários.

Segundo Kotler e Armstrong (2007), a análise de portfólio é fator fundamental durante o planejamento estratégico. Isso porque contribui para a avaliação dos produtos e serviços de uma empresa em relação ao investimento em negócios que geram mais lucro e ao mesmo tempo evita investimentos em negócios que apresentem resultados menos significativos. Nesse sentido, o planejamento estratégico visou diagnosticar quais as formas de uma empresa analisar seu ambiente e tirar proveito das oportunidades que o mercado oferece, explorando seus pontos fortes. Após a síntese dos resultados das entrevistas, ficou evidente que a empresa estudada estava de acordo com o que os autores afirmaram, uma vez que a empresa primeiramente utilizou a ferramenta de análise SWOT, siga em inglês para as palavras "Strengths" (Forças), "Weaknesses" (Fraquezas), “Opportunities" Oportunidades e "Threats" (Ameaças), visando diagnosticar seus pontos fortes e fracos em relação às ameaças e oportunidades que o ambiente oferece. Conjuntamente com a análise SWOT, a empresa analisou a compilação das respostas das avaliações de reação com o objetivo de identificar junto a seus clientes possíveis recompras, com a indicação de títulos de cursos que gostariam de comprar. Foi mantido ainda um canal de comunicação com os consumidores via Internet, através do site da empresa, para que os mesmos registrem seus interesses em cursos e eventos. Por fim, uma equipe local, composta por gestores e docentes especialistas das mais diversas áreas de negócios que a empresa atua, discutem, anualmente, o planejamento da oferta para o próximo ano, visando o diagnóstico dos cursos que estão em alta, áreas 
emergentes e expectativas do mercado. Dessa forma, fica evidenciado que a empresa realizou a atualização de seu portfólio em busca de maior assertividade na oferta e de vantagem competitiva.

\section{Preço}

O segundo item do mix de marketing analisado foi o preço, com o intuito de verificar se os preços adotados na comercialização dos serviços educacionais são praticados de forma competitiva e se os mesmos atendem às expectativas dos clientes e à realidade do mercado local. Outro ponto de análise foi diagnosticar se a empresa estudada possui uma política de preços e descontos para comercialização de seus serviços e se essa política é percebida pelos consumidores como forma de atração para compra dos serviços e fidelização de clientes. Finalizando os estudos sobre o elemento preço, o intuito foi reconhecer se a empresa utiliza os preços como estratégia para seu posicionamento mercadológico.

Em relação à discussão sobre os preços e descontos praticados, as entrevistas demonstraram que a empresa estudada possui uma política de preços baseada na localização de suas unidades de negócios, especificamente no mercado regional em que atua. Ainda assim, os preços praticados sempre foram mais altos que os da concorrência, visando cobrir os custos dos investimentos na qualidade de toda sua infraestrutura, material didático e na qualificação de suas equipes administrativas e pedagógicas. No início do ano de 2017, a empresa adotou uma política de descontos pontual, com taxas significativas entre 30\% e 40\% de desconto. Essa ação proporcionou maior acesso aos serviços que a empresa oferece e promoveu consequente aumento na procura e comercialização de seus serviços, aumentando assim sua competitividade. Em função do resultado obtido, a empresa estuda a manutenção dessa política de descontos para o próximo ano. Foi possível observar, após a análise das entrevistas, que a empresa estudada está de acordo com os preceitos da literatura. Como afirmou Kotler (2005), as empresas determinam seus preços com base na demanda de mercado, custos operacionais, localização geográfica, além de outros fatores que podem determinar a formação dos preços e é exatamente isso que ocorre na empresa.

Relacionado ainda à política de preços e descontos, foi possível averiguar nas entrevistas que a empresa estudada tem sua política bastante divulgada e reconhecida por seus consumidores. A empresa utiliza seu portal "online" e demais mídias sociais para comunicar claramente sua política de preços e descontos, além de apresentá-la estrategicamente em toda ação de relacionamento com o cliente. Conforme citado anteriormente, a política de preços e descontos considera a localização geográfica de cada unidade da empresa, além de oferecer descontos a trabalhadores das áreas de comércio e serviços, ex-alunos, pontualidade no pagamento e grupos de pessoas de uma mesma família ou empresas. Outro fator importante é a política de bolsas de estudos que a empresa oferece, com objetivos sociais de oportunizar às pessoas de baixa renda o acesso aos cursos e eventos ofertados e consequente qualificação para o mercado de trabalho. Ficou evidenciado através dos dados coletados que a empresa estudada está de acordo com Cravens e Piercy (2007) sobre a política de preços e descontos. Os autores afirmaram que descontos, devoluções, abonos e outros direcionamentos operacionais podem fazer parte de uma política de preços e que a estratégia de preços tem como fundamento as políticas de descontos adotadas pela empresa.

Finalizando a análise sobre o elemento preço, Churchill Jr e Peter (2003) afirmaram que o preço pode contribuir para o posicionamento de um produto em relação ao mercado, desde que esteja alinhado a outros elementos do mix de marketing, uma vez que potenciais clientes são influenciados pelo preço em sua decisão de compra. Nas entrevistas realizadas não houve um consenso sobre a questão, uma vez que parte dos entrevistados acreditam que os preços praticados são utilizados como estratégia para o posicionamento da empresa estudada no mercado, principalmente após à referida política de preços e descontos praticada no ano de 2017. O Docente especialista e o Coordenador administrativo acreditaram que outros fatores, tais como a qualidade das instalações e infraestrutura, o investimento na qualificação dos profissionais e principalmente a força da marca e credibilidade junto aos consumidores, determinaram seu posicionamento mercadológico.

\section{Praça (Distribuição)}

Após a análise do serviço e do preço, a praça (distribuição) foi o elemento do mix de marketing abordado nas entrevistas. No início dos estudos sobre o elemento praça o objetivo foi verificar se os clientes percebem como valor a infraestrutura educacional que a empresa estudada oferece e de que forma isso foi percebido por seus clientes. Na sequência foi feita uma análise sobre a localização das unidades onde a empresa estudada oferece e realiza seus serviços e o quanto a localização contribui para o deslocamento e permanência dos clientes nas referidas unidades, especialmente em relação a acesso, estacionamento e segurança. Finalizando a abordagem sobre o elemento praça, foi indispensável conhecer a importância das parcerias para a empresa estudada na ampliação de sua oferta de serviços.

Durante a análise dos dados, foi importante diagnosticar que a infraestrutura educacional ofertada pela empresa estudada foi um aspecto de muito valor e destaque para os clientes da empresa. Nas avaliações de reação, bem como nos escritos do projeto político 
pedagógico da unidade, foram encontrados inúmeros relatos com elogios principalmente à qualidade das instalações físicas, limpeza e organização das salas de aulas, laboratórios, salas multifuncionais e equipamentos utilizados. Também foi elogiada a oferta de espaços diferenciados não só para a realização das ações educacionais, mas também para a convivência dos alunos. Aspectos como a capacidade e a qualificação profissional, além da forma como se apresentam os profissionais que entregam os serviços também foram amplamente citados.

De acordo com a Supervisora educacional e o Docente especialista, a unidade buscou incessantemente tornar as instalações físicas cada vez mais acessíveis a todo tipo de público, inclusive com a forte preocupação quanto à acessibilidade para pessoas com deficiência. Foi relatado ainda por um dos Técnicos de desenvolvimento educacional que toda essa qualidade pode vir a demonstrar que a empresa tem como foco atender principalmente o público das classes sociais A e B, porém essa impressão termina assim que o cliente tem um primeiro contato com a empresa estudada. Preocupada com essa questão e visando atrair e proporcionar esse primeiro contato com toda sociedade, a empresa vem realizando ações tais como: o evento casa aberta, ou seja, um dia que a empresa abre suas portas para que o público em geral possa conhecer suas instalações e experimentar os principais serviços ofertados em seu portfólio através de palestras, oficinas, exposições e minicursos; elaboração do projeto político pedagógico com a participação da comunidade interna e externa da empresa estudada; realização de eventos externos e a frequente participação em campanhas públicas de saúde e outras áreas, além da política de descontos e bolsas de estudos que visa atender ao público de menor renda. Desse modo, a pesquisa constatou que a empresa baseou na literatura existente.

Segundo Zeithaml e Bitner (2003), os clientes rotineiros e principalmente os clientes entrantes utilizaram as condições de toda infraestrutura, bem como a aparência dos funcionários e das peças de comunicação, como forma de analisar e fazer uma avaliação da qualidade, tornando assim a imagem dos serviços tangível. Ainda de acordo com Zeithaml e Bitner (2003), componentes tangíveis facilitaram toda comunicação com o cliente, bem como o desempenho de um produto. Assim, qualquer evidência física pode comunicar e facilitar o desempenho de um serviço no ambiente em que é ofertado e realizado.

Um fato importante identificado nas entrevistas realizadas foi que a empresa pode ter suas evidências físicas relacionadas a acesso, segurança e estacionamento comprometidas. Isso porque suas unidades estão estrategicamente localizadas nas regiões centrais das cidades, sejam próprias ou em parceria. As citadas localizações permitiram facilitar o acesso de seus clientes, tendo em vista a ampla rede de transporte público que atende as referidas regiões. Por outro lado, o estacionamento nas imediações ficou bastante comprometido em função do alto fluxo de veículos por conta do grande número de estabelecimentos comerciais nas regiões centrais. Consequentemente, houve alta demanda por vagas de estacionamento e a empresa em conjunto com seus parceiros não consegue ofertar o número de vagas suficiente para atender a demanda de seu público. Nesse sentido, pode ocorrer o comprometimento da segurança física de seus clientes e dos veículos que os mesmos utilizam para se deslocarem até as unidades e ali permanecerem. Preocupada com isso, a empresa buscou o apoio da guarda municipal e da polícia militar, solicitando rondas frequentes nos horários de maior fluxo de consumidores nas ações que a empresa promove.

Os dados coletados também permitiram afirmar que as parcerias foram de fundamental importância para que a empresa estudada possa levar através de seus serviços, qualificação profissional para as pessoas de outras cidades da região. $\mathrm{Na}$ opinião de todos os entrevistados, esse público dificilmente se deslocaria até a unidade localizada na cidade de São Carlos para ter acesso aos serviços ofertados, em função dos custos dos cursos e consequentes despesas com transporte, alimentação, pedágios, dentre outros. As parcerias, além de gerarem tal oportunidade aos clientes, estrategicamente, diminuem o espaço ocupado pela concorrência e fortalecem a marca institucional da empresa estudada nas cidades da região em que atua. Assim, fica nítido que a empresa estudada realiza na prática o que a literatura preconiza, especificamente através de Kotler e Keller (2012), que afirmaram que em uma visão ampliada, as empresas devem criar um sistema de parcerias visando aumentar a capilaridade de seus produtos e serviços. Isso possibilita a criação de uma rede de valor, na qual a empresa fica no centro em relação a seus parceiros.

\section{Promoção}

A promoção foi o último elemento do mix marketing analisado, tendo como objetivo verificar se a empresa estudada procura integrar as ações de comunicação de marketing através do marketing integrado ou opta por comunicações pontuais e individualizadas. Outro fator importante relacionado à promoção foi saber se a empresa estudada utilizou diferentes mídias como forma de propaganda e se as mídias utilizadas atingem os nichos de mercado esperados. Para finalizar a análise do elemento promoção, foi significativo identificar quais as melhores formas de desenvolver ações de propaganda e atrair publicidade a fim de fortalecer a marca e conquistar vantagem competitiva para a empresa estudada. 
Para Las Casas (2015), as empresas precisam comunicar uma única mensagem, promovendo o marketing integrado que transforma a publicidade, a promoção de vendas, a assessoria de imprensa e demais elementos da comunicação em um sistema integrado de comunicação. Através do resultado das entrevistas, ficou caracterizado que a empresa estudada realiza ações de comunicação integrada e ações de comunicações mais pontuais e regionalizadas, tendo em vista o fato da unidade estudada fazer parte de uma rede que compõe a empresa como um todo. A empresa no âmbito dessa rede realizou estrategicamente ações de comunicação institucionais e mercadológicas, visando promover seu portfólio de cursos e também sua marca, além de evidenciar seu posicionamento frente ao mercado. A unidade da empresa estudada realizou ainda ações de comunicação mais pontuais e focadas em seus objetivos e metas, visando promover sua oferta de cursos e eventos em períodos específicos, de acordo com sua programação anual e verba destinada para comunicação.

Referente a utilização dos diferentes tipos de mídias, a síntese das entrevistas demonstrou que a empresa dedica suas ações de comunicação em canais como outdoor, propaganda em rádio, internet e mídias sociais. Observou que tais canais atingiram principalmente o público de massa e não exploram os públicos mais específicos. Os relatos dos profissionais sugeriram que seria ideal a realização de um planejamento local para a definição das ações de propaganda, com a segmentação do mercado-alvo, visando usar canais de comunicação adequados a cada tipo de público e assim atingir nichos específicos de forma estratégica. Percebeu que a empresa estudada não estava alinhada totalmente com o que aborda a literatura sobre o tema. Os profissionais de marketing precisam identificar quais as mídias adequadas para o posicionamento dos produtos de uma empresa baseados nos hábitos de seus consumidores, localização e até mesmo a exposição à mídia, levando em conta ainda os seus custos (Churchill Jr e Peter, 2003).

Ries e Jack (2009) afirmaram que as empresas precisam buscar ser as primeiras nas lembranças de seus potenciais clientes. Isso porque a sociedade está cada vez mais comunicativa e a publicidade precisa ser desenvolvida de forma estratégica, com destaque aos pontos fortes e fracos em comparação aos dos concorrentes. O intuito assim, foi buscar se posicionar na mente do potencial cliente. Nesse sentido, para a maioria dos entrevistados a empresa estudada precisa investir mais em comunicação para estar de acordo com o que se encontra na literatura. Esse investimento deve acontecer com o objetivo de atingir públicos específicos e segmentos de mercado que ainda não têm conhecimento da marca. De acordo com os profissionais entrevistados, o marketing de referência continua sendo a melhor forma de divulgar a marca da empresa, porém seria importante que a empresa estudada investisse em campanhas institucionais com foco na divulgação de sua marca e de suas ações, bem como na busca pela expansão de parcerias. Dessa forma, seria possível promover não só o fortalecimento da marca, mas também o aumento de visibilidade no mercado e a consequente ampliação do número de clientes, conquistando assim maior vantagem competitiva.

\section{Considerações Finais}

O estudo realizado permitiu identificar a importância do mix de marketing na comercialização de itens educacionais, que se relacionam a seus quatro elementos.

Quanto ao elemento produto do mix de marketing, constou-se que em as decisões de compras os consumidores da empresa estudada dão importância principalmente à força da marca, qualificação profissional, qualidade do atendimento e entrega dos serviços, bem como a constante atualização do portfólio. No que se refere ao elemento preço, notou-se que a empresa possui uma política de preços e descontos bem definida e reconhecida por seus clientes. A adoção em 2017 de uma política de preços com descontos consideráveis alavancou suas vendas e a tornou mais competitiva frente à concorrência, uma vez que seus preços sempre foram mais altos. Quanto ao elemento praça, identificou que a empresa investiu na excelência de sua infraestrutura e na qualificação de seus profissionais, além de buscar maior capilaridade com a manutenção de parcerias em outros municípios e investimento em acessibilidade. Essas ações tornaram a oferta mais acessível a todo tipo de público e consequentemente, diminuíram o espaço ocupado pela concorrência.

Finalmente, em relação ao elemento promoção, houve a percepção que a empresa realizou ações promocionais pontuais para a divulgação de seus produtos, de modo a atingir principalmente o público em grande escala. $\mathrm{O}$ estudo sugeriu que a realização de ações promocionais voltadas à segmentação do mercado seja ampliada, visando assim atingir públicos específicos e tornar a marca ainda mais conhecida.

Desse modo, conclui-se que empresa estudada entende a importância do mix de marketing e investe em seus quatro elementos para a comercialização de serviços e eventos educacionais. O referido investimento alavanca suas vendas e gera valor para os clientes, com consequente conquista de vantagem competitiva.

\section{Referências}

Besanko, D.; Dranove, D.; Shanley, M.; Schaefer, S. 2012. A Economia da estratégia. Artmed Editora S.A., Porto Alegre, RS, Brasil.

Churchill Jr, G.A.; Peter, J.P. 2003. Marketing: criando valor para os clientes. Editora Saraiva, São Paulo, SP, Brasil. 
Colombo, S.S. 2008. Marketing educacional em ação. Artmed Editora S.A, Porto Alegre, RS, Brasil.

Cravens, D.W.; Piercy, N.F. 2007. Marketing estratégico. McGraw-Hill, São Paulo, SP, Brasil.

Fitzsimmons, J.A.; Fitzsimmons, M.J. 2014. Administração de serviços: operações, estratégia e tecnologia da informação. AMGH Editora Ltda, Porto Alegre, RS, Brasil.

Hooley, G.J.; Piercy, N.F.; Nicoulaud, B. 2011. Estratégia de marketing e posicionamento competitivo. Pearson Prentice Hall, São Paulo, SP, Brasil.

Instituto Brasileiro de Geografia e Estatística [IBGE]. 2010. Cidades. Disponível em: <https://cidades.ibge.gov.br>. Acesso em: 04 jun. 2017.

Kotler, P. 2005. Marketing essencial. Editora Prentice Hall, São Paulo, SP, Brasil.

Kotler, P.; Armstrong, G. 2007. Princípios de Marketing. Editora Pearson Prentice Hall, São Paulo, SP, Brasil.

Kotler, P.; Keller K. L. 2012. Administração de Marketing. Pearson Education do Brasil, São Paulo, SP. Brasil.

Las Casas, A.L. 2015. Administração de marketing: conceitos, planejamento e aplicações à realidade brasileira. Atlas, São Paulo, SP, Brasil.

Ries, A.; Trout, J. 2009. Posicionamento: a batalha por sua mente. M. Books do Brasil Ltda, São Paulo, SP, Brasil.

Schwab, K. 2016. A quarta revolução industrial. Edipro, São Paulo, SP, Brasil.

Zeithaml, V.A.; Bitner, M.J. 2003. Marketing de serviços: A empresa com foco no cliente. Bookman, Porto Alegre, RS, Brasil.

Zeithaml, V.A.; Bitner, M.J.; Gremler, D.D. 2014. Marketing de serviços: A empresa com foco no cliente. AMGH Editora Ltda, Porto Alegre, RS, Brasil. 